\title{
A representação de atores sociais em comentários eletrônicos: que figuras habitam o imaginário político dos brasileiros na atualidade?
}

Anna Elizabeth Balocco ${ }^{a}$

\begin{abstract}
Resumo
A proposta do artigo é examinar o imaginário político brasileiro após a eleição da presidente Dilma Roussef, por meio de investigação da representação discursiva de atores sociais em comentários eletrônicos, publicados em um site de notícias. Para tanto, são utilizados o argumento de Laclau \& Mouffe (1985) pela nature$z a$ aberta do social e das identidades coletivas, assim como os conceitos de discurso polêmico (AMOSSY, 2011), de ideologia (EAGLETON, 1991; PEDRO, 1997) e de imaginário social (FAIRCLOUGH, 2015; CASTORIADIS, 1982). A partir de quadro analítico de Van Leeuwen (1996) para o estudo da representação de atores sociais no discurso, são identificados três tipos de atores sociais no corpus; apontadas algumas correlações entre posicionamento discursivo e representação de atores sociais; além de feitas algumas considerações sobre a natureza heterogênea e dinâmica do imaginário social.
\end{abstract}

PALAVRAS-CHAVE: representação de atores sociais; comentários eletrônicos; discurso polêmico; imaginário social. 


\section{Introdução}

A linguagem hostil e agressiva tem sido estudada de diferentes perspectivas no âmbito dos estudos da linguagem. Culpeper (2012) toma o arcabouço teórico de Brown \& Levinson (1987), sobre o fenômeno da polidez, como ponto de partida para a análise de aspectos linguísticos da 'linguagem usada para ofender'. Amaral (2012) é uma dissertação de mestrado que examina o funcionamento discursivo de um dispositivo digital (o Twitter) e que traz vários achados relevantes para o estudo da relação entre linguagem agressiva e mídia digital. O fenômeno do flaming, ou violência verbal em mídia digital, também é estudado por Balocco \& Shepherd (2016) e por Amossy (2011). Esta última autora argumenta que a linguagem agressiva e polarizada, embora possa ser relacionada a alguns traços da mídia digital, não resulta exclusivamente desta.

Este estudo contribui para esta última tradição de pesquisas, ao relacionar os traços de um corpus de textos coletados em um site de notícias a características do discurso polêmico. Sua proposta não é olhar para o comportamento verbal dos internautas como comportamento que foge às regras de convívio social, mas como uma intervenção discursiva no âmbito de debates públicos.

Os posts em sites de notícias são uma nova forma de mediação entre o público e o privado, que permite a aparição de novas formas de subjetividade. Os internautas expressam suas opiniões aberta e livremente, além de trocarem insultos sem o menor constrangimento e, ao fazerem isso, materializam, no seu discurso, um imaginário habitado por diferentes atores sociais. Tendo em vista a opacidade constitutiva das relações sociais e das identidades coletivas, que são frágeis e sempre em disputa, que figuras habitam o nosso imaginário político? Que traços caracterizam a construção de identidades coletivas no Brasil, diante da complexidade e da pluralidade de demandas que caracterizam o cenário político da atualidade?

Os comentários eletrônicos, em sites de notícias, compartilham com as cartas do leitor, no jornalismo impresso, o fato de serem espaços bem demarcados que não obedecem aos princípios e às regras do jornalismo (BALOCCO, 2010). São textos opinativos, em que os locutores expressam seus pontos de vista em relação a temas veiculados no jornal. Por outro lado, 
diferentemente do que ocorre com as cartas do leitor em jornais, nos comentários eletrônicos em sites de notícias, tudo pode ser dito e publicado, pois eles não são editados. Além desse traço, possibilitado pelas características da mídia digital, abre-se a possibilidade de interação, em tempo real, entre internautas, a respeito de um mesmo tema político.

Os comentários (ou posts) eletrônicos são publicados em diferentes sites da internet; há comentários em blogs, em sites de notícias, em redes sociais, como o Facebook, ou o Twitter, dentre várias outras possibilidades. O presente trabalho centra-se unicamente na análise de comentários em sites de notícias, com o objetivo de levantar questões relevantes para os estudos do discurso e das práticas sociais.

Para reunir elementos para esta reflexão, será brevemente apresentado o enfoque discursivo à vida social de Laclau \& Mouffe (1985) e Laclau (2005; 2007), feitas considerações sobre o comentário eletrônico e sua funcionalidade, além de explicitados os conceitos de discurso polêmico, ideologia e imaginário social. Com base nesses elementos e na análise empírica de comentários eletrônicos postados no site de notícias O Globo, a partir das categorias de van Leeuwen (1996) para o exame da representação de atores sociais no discurso, será investigado o imaginário que caracteriza a cena política brasileira hoje e o processo de construção discursiva de identidades coletivas.

Argumenta-se, neste estudo, pela relevância de pesquisas que tomem o imaginário social como objeto, por sua importância no entendimento da forma como se percebem e se constroem narrativas sobre temas políticos, ou de qualquer outra natureza. A pesquisa linguística tem muito a oferecer à pesquisa em outras áreas das ciências humanas e sociais, por seu trabalho metodológico, criterioso e fundamentado na área do discurso e das práticas sociais.

\section{A natureza aberta do social}

Laclau\&Mouffe (1985, p. 151) argumentam que o campo social não tem um caráter fechado e que as relações sociais não são fixas, ou pré-determinadas, mas constituídas de forma distinta ao longo da história. Correndo o risco de reduzir o 
argumento dos autores, resumimos alguns pontos relevantes para esta pesquisa. Os pesquisadores argumentam, por exemplo, que no imaginário marxista das décadas de 20 e 30 do século XX, o espaço político é representado como lugar de embates entre a burguesia, de um lado, e a classe trabalhadora, de outro. Já no imaginário democrático, que se constrói a partir dos movimentos sociais protagonizados pelos negros, pelas mulheres e por minorias étnicas, a partir das décadas de 60 e 70 do mesmo século, o campo social é habitado por diversos atores políticos, com diferentes tipos de demandas e de atuação na arena pública.

Esta configuração do campo social leva à impossibilidade de se definir, de antemão, o sentido de qualquer luta: não há atores políticos, em posições privilegiadas, que representem vetores de transformação da sociedade (a classe trabalhadora, ou os intelectuais). Os antagonismos sociais são entendidos como 'significantes flutuantes' (ibidem, p. 171), ou seja, eles não antecedem as lutas políticas e não são constituídos a partir de parâmetros transparentes, mas constituem-se nas próprias lutas políticas, ou na tentativa de negociação de demandas no espaço público.

Também as identidades coletivas são vistas como significantes flutuantes, nesse quadro teórico. Elas não são fechadas em si mesmas, mas constituem-se como diferença, sendo definidas em relação às outras identidades com as quais disputam o espaço público. Por exemplo, diante da complexidade e da pluralidade das demandas no capitalismo moderno, as identidades coletivas não se constituem mais exclusivamente em termos de classe social (o povo, a burguesia, a elite), mas em diferentes dimensões. É para os parâmetros usados nessa construção discursiva que se volta esta pesquisa.

\section{Comentários em sites de notícias: discurso político ou midiático?}

Para Pinto (2012, p. 79), o discurso político é geralmente reconhecido com base em seus lugares de enunciação tradicionais, ligados a figuras públicas, políticos ou representantes do Estado (em pronunciamentos públicos, ou em falas/textos de circulação no âmbito local, nacional 
1 Para uma discussão mais alentada dos problemas de uma definição muito ampla de discurso político, que termina por se confundir com o discurso público, veja Van Dijk (obra citada no mesmo parágrafo). e internacional, como sessões no parlamento, campanhas eleitorais, discursos oficiais, entrevistas). A mesma autora adverte, no entanto, que o discurso político hoje abrange novos espaços de enunciação, que colocam em cena não somente os emissores tradicionais do discurso político, mas também seus receptores, que encontram espaço na mídia para se pronunciar a respeito de temas de seu interesse. Os comentários eletrônicos poderiam, assim, ser vistos como novos espaços de articulação do discurso político.

Nesta pesquisa, no entanto, adota-se critério de Van Dijk (1997, p. 15) para a identificação do discurso político: para o autor, a categorização de determinado discurso como político depende de sua funcionalidade sobre processos políticos, ou de o mesmo ter influência, direta ou indireta, sobre determinado processo político. Embora tratem de temas políticos, os comentários eletrônicos não são diretamente funcionais nos processos políticos, ou seja, não são discursos produzidos em fóruns políticos, com repercussões sobre aqueles processos, sendo, portanto, tratados, nesta pesquisa, como localizados no âmbito do discurso público midiático ${ }^{1}$.

Os comentários eletrônicos em sites de notícias, estudados nesta pesquisa, textualizam-se na forma de um discurso polêmico, que se caracteriza pela tentativa de desconstrução do outro, com farta ocorrência de violência verbal (insultos, injúrias, xingamentos, desqualificação do outro).

Discurso polêmico, ideologia, discurso e imaginário social

Para Amossy (2011), o discurso polêmico é uma prática discursiva destinada a destruir o adversário, caracterizada pela pressuposição de um contradiscurso antagonista. Segundo a autora, a polêmica pode ou não se expressar em linguagem agressiva e violenta, mas caracteriza-se necessariamente "pela polarização extrema e pela confrontação radical de posições antagonistas".

A pesquisa de Amaral (2012) sobre a interação verbal em dispositivos digitais, embora de escopo limitado e em mídia distinta (Twitter), relata resultados em que a ocorrência de linguagem de baixo calão e agressiva é motivada, não somente pela interação em tempo real, em contexto situacional de 
2 Para o autor, as formações discursivas são matrizes de sentido que, em uma formação ideológica específica e em dado momento histórico, afetam o que pode e o que deve ser dito.

3 Cf. Castoriadis (1982, p. 13): “[...] O imaginário não é a partir da imagem no espelho ou no olhar do outro. O próprio espelho, e a sua possibilidade, e o outro como espelho são antes obras do imaginário que é criação exnihilo. Aqueles que falam de 'imaginário' compreendendo por isso o 'especular', o reflexo ou o 'fictício', apenas repetem, e muito frequentemente sem o saberem, a afirmação que os prendeu para sempre a um subsolo qualquer da famosa caverna: é necessário que (este mundo) seja imagem de alguma coisa. O imaginário de que falo não é imagem de. É criação incessante e essencialmente indeterminada (social-histórica e psíquica) de figuras/ formas/ imagem, a partir das quais somente é possível falar-se de "alguma coisa". Aquilo que denominamos 'realidade' e'racionalidade' são seus produtos". grande envolvimento emocional (jogos da Copa do Mundo), mas também pela distância social entre os participantes do evento discursivo. No entanto, não se observa, ali, a polarização e a confrontação de posições antagônicas que caracterizam o discurso polêmico.

O discurso polêmico, com sua encenação de uma disputa entre diversos atores sociais, não ocorre em um vácuo, mas no interior de determinada formação discursiva (FOUCAULT, 19872). Quando emitem opiniões (a favor ou contra a presidente), os internautas o fazem no interior de um conjunto de posições discursivas, controlado e estruturado por certa ideologia.

A partir desse entendimento, foi preciso trazer para o arcabouço teórico desta pesquisa o conceito de ideologia. Optou-se por uma ideologia do discurso, em que se contam os efeitos discursivos concretos, mais do que as significações; uma ideologia do conflito e da contradição (EAGLETON, 1991, p. 222) que subscreve a uma visão relacional do poder, em que este último não é algo possuído apenas por um grupo, mas permanentemente disputado por diferentes atores sociais (PEDRO, 1997, p. 38); uma ideologia que comporta dimensões afetivas, inconscientes, imaginárias e simbólicas que constituem a experiência vivida do sujeito.

O conjunto das imagens e representações de certo grupo social, atualizado em seus discursos, delineia certo imaginário que não é algo em contraste com o real, ou algo irreal, mas da ordem da imagem. O conceito de imaginário serve para chamar atenção para a forma como a linguagem esquece, por assim dizer, as relações contingentes e acidentais (e não orgânicas ou inevitáveis) que tem com aquilo que representa (EAGLETON, 1991, p. 200).

Para Castoriadis (1982, p. 13), o imaginário não é especular, não reflete, mas cria imagens, representações e discursos ${ }^{3}$. Nesta linha da natureza produtiva do imaginário, Fairclough $(2015$, p. 3) argumenta que o mesmo comporta uma dimensão normativa, ao incluir "representações de como as coisas poderiam ou deveriam ser". O que encontramos no discurso dos internautas, por exemplo, não são descrições de categorias empíricas (a presidente, o sistema de governo, o sistema político), mas imagens que fazem do que poderia ou deveria ser um bom presidente, um bom governo, a boa política. 
Tendo apresentado as relações entre discurso, ideologia e imaginário, resta, para fechar o quadro conceitual deste estudo, observar que o imaginário social é constituído de acontecimentos, personagens e lugares sociais. Esta pesquisa volta-se exclusivamente para os personagens ou atores sociais que habitam o imaginário político no Brasil, desde a primeira década do século XXI, tal como expresso no discurso de internautas.

\section{Metodologia}

A coleta de textos para o corpus de estudo aconteceu durante o período pós-eleitoral: a primeira coleta de comentários foi feita em 10/08/2015, após notícia sobre a participação do senador Aécio Neves em evento público, em que convoca os brasileiros a aderirem a manifestação contra a presidente Dilma Roussef. A segunda coleta foi em 11/08/2015, após notícia sobre o presidente Lula e a Marcha das Margaridas, convocada para dar apoio à presidente.

Embora não se trate de campanha eleitoral, os candidatos e os internautas que postam comentários comportam-se como se estivessem em campanha, tendo em vista a possibilidade de impeachment da presidente Dilma. Pode-se, assim, afirmar que se trata de uma situação, senão de conquista de poder, pelo menos de garantia de poder conquistado nas urnas, de um lado, e de ameaças ao poder, de outro. Isso, por si só, motiva a ocorrência de linguagem radical e polarizada no corpus.

Entende-se que, para maior representatividade do corpus desta pesquisa, será necessário constituir posteriormente outros subcorpora, em contextos situacionais diversos. Mas para este artigo, de caráter exploratório, entendeu-se que os comentários às notícias acima descritas seriam suficientes para algumas considerações preliminares sobre a representação de atores sociais no discurso de internautas.

Um desafio para a análise da linguagem digital é a definição de texto. O que constitui um texto em sites de notícias, além da notícia propriamente dita? Cada comentário individual é um texto em si, ou apenas um enunciado? Dada a natureza interacional dos comentários, em que os internautas respondem a postagens uns dos outros, seria mais conveniente, analiticamente, tratar os comentários individuais como turnos 
conversacionais? Dados os objetivos deste estudo, voltados para a representação discursiva dos atores sociais, os comentários individuais (uma única mensagem na conta de um usuário) são tratados como textos. Havendo mais de um comentário de um mesmo usuário, o mesmo é tratado como outro texto, ou seja, as mensagens na conta de um só usuário não foram agrupadas para formar um texto.

O que garante heterogeneidade ao corpus é a própria mídia e o gênero, que reúne, em um só espaço, a opinião de internautas de diferentes posições políticas (ou alinhados a diferentes formações discursivas). Embora não tenhamos acesso às características desses locutores, pode-se afirmar, com relativa segurança, que são adultos, letrados, com predominância de homens (em relação a mulheres), e com o hábito de leitura de jornais. Uma variável que talvez deva ser problematizada é a natureza do site em si, em que foram coletados os comentários. O posicionamento do jornal O Globo pode influenciar o comportamento do seu público leitor; no entanto, a julgar pela análise empírica dos comentários aqui coligidos, os internautas não se alinham automaticamente ao jornal, havendo dois tipos de posicionamento interpessoal, como será discutido adiante.

Para garantir a anonimidade dos internautas, embora o site seja de domínio público, decidiu-se pelo uso de iniciais para identificar os comentários publicados. Alguns internautas usam apelidos em suas postagens, outros usam seus nomes completos, ou apenas os seus nomes de batismo. É com base nessas estratégias de identificação que se sugere que há predominância de homens como locutores, no corpus.

Os fragmentos retirados do corpus são identificados, em primeiro lugar, por sua ocorrência após a primeira notícia (SC1, subcorpus 1) ou após a segunda notícia (SC2, subcorpus 2), para que se possa investigar se há correlação entre características do comentário e o teor da notícia (em termos discursivos, o tópico). Em segundo lugar, anotam-se as iniciais dos internautas. Os comentários são apresentados sem revisão, da forma como publicados, com erros de gramática, de pontuação, de ortografia, dentre vários outros. 
Tabela 1 - Perfil do corpus

\begin{tabular}{|l|c|c|c|c|}
\hline Corpus estudo & Participantes & Comentários & No. de Palavras & Publicação \\
\hline Subcorpus $1^{4}$ & 19 & 67 & 1.422 & $11 / 08 / 2015$ \\
\hline Subcorpus $2^{5}$ & 31 & 29 & 2.962 & $10 / 08 / 2015$ \\
\hline Total Corpus & 50 & 96 & 4.384 & - \\
\hline
\end{tabular}

A relação entre o número de participantes e o de comentários atesta a densidade das trocas interacionais no site de notícias. Os participantes postam seus comentários, mas também respondem a outros internautas, ou os atacam.

No que diz respeito ao tratamento dos dados, foram adotadas as categorias analíticas e o quadro teórico de Van Leeuwen para o estudo da representação discursiva de atores sociais, que permitem a investigação da inclusão ou exclusão de atores sociais no discurso, além da forma como esses atores são discursivamente representados. Mediante essas categorias, de natureza sociodiscursiva, mas sempre ligadas a realizações lexicogramaticais específicas, é possível responder às perguntas de pesquisa voltadas para a constituição do imaginário social e de identidades coletivas.

\section{Levantamento de dados}

Os atores sociais no corpus são, segundo categorias de Van Leeuwen, individualizados, nomeados, ativados, e, às vezes, funcionalizados:

- SC1.ALF. há 18 minutos: O governo da presidente Dilma

4 Disponível em http:// oglobo.globo.com/brasil/lula-dilma-apostam-em-movimentos-sociais-para-contrapor-acoes-de-oposicionistas-17145765. Acesso em 11 ago. 2015.

5 Disponível em http:// oglobo.globo.com/brasil/aecio-diz-que-nao-cabe-ao-psdb-escolher-melhor-desfecho-para-crise-17143221. Acesso em 11 ago. 2015. nesse momento está mais perene que a relva, tentar evitar um protesto Democrático via rede social usando UNE e o MST, mostra a fraqueza do governo, (...). [individualização; nomeação; funcionalização; ativação]

- SC1.RS. há 1 hora: Aécio Neves e Eduardo Cunha, Os Achacadores do Brasil, convocam para o próximo domingo a Elite e os Eleitores do PSDB, torcida do quanto pior o Brasil ficar, melhor para satisfazer o ego pessoal, para o Golpe na Democracia. [individualização; nomeação; ativação] 
Os atores sociais são representados como ativados, nos posts, ou seja, assumem papel ativo no discurso (a presidente tenta evitar um protesto; o senador e Eduardo Cunha convocam para o protesto). No primeiro post, Dilma é categorizada através de funcionalização, em que se especifica a atividade do ator social (a presidente Dilma). Embora não seja o caso do segundo post, também há ocorrências de funcionalização de Aécio Neves no corpus, como a seguir:

- SC2.FFD. há 4 horas: Senador Aécio, desça do palanque, (...) [funcionalização]

Neste post, há dupla funcionalização: além da lexicalização "senador", a localização do senador em um palanque serve para caracterizá-lo como alguém em campanha política. Sobressai, do comentário, a forma híbrida de nomeação, que combina informalidade (nome) e formalidade (sua função como senador), a par do uso da forma imperativa, usada em contextos onde há grau mínimo de distância social entre os participantes do discurso. O uso de marcas de proximidade social percorre todo o corpus, como no exemplo a seguir, em que se observa também, ainda no âmbito da individualização dos atores sociais, a estratégia de identificação com base em classe social:

- SC2.AF. há 16 horas: Para Miami já, "pray-boy" capiau! [individualização; valoração]

Neste post, além de dirigir-se ao senador em registro íntimo, de grande aproximação social (ele dá ordens ao senador), o internauta usa marcas de valoração negativa ("capiau") e de identificação social ("pray-boy").

Contrastando com a especificação dos atores sociais no discurso, através de individualização/nomeação, observa-se a ocorrência de assimilação de atores sociais em grandes grupos, como nos exemplos a seguir:

- SC1.RS. há 1 hora: Aécio Neves e Eduardo Cunha, Os Achacadores do Brasil, convocam para o próximo domingo a Elite e os Eleitores do PSDB, torcida do quanto pior o Brasil ficar, melhor para satisfazer o ego pessoal, para o Golpe na Democracia [assimilação] 
- SC1.AJL. há 41 minutos: Enquanto eles não largam o osso, quem sofre é o Povo....Bando de oportunistas. [assimilação]

- SC1.LA. há 57 minutos: Vai convocar os baderneiros para tumultuar as manifestações pacíficas de brasileiros cansados de corrupção e desprezo. [assimilação]

Nos exemplos, os atores sociais são identificados em coletivos valorizados de forma negativa ("a Elite"; "a torcida do quanto pior melhor"; "bando de oportunistas"; "os baderneiros"). Nessa estratégia de construção do outro imaginário, o que varia são os pontos de identificação em que se apoia a construção de identidades coletivas. Por exemplo, em "a Elite", a categorização do grupo assimilado é feita em termos de identificação com base em classe social. Já em "bando de oportunistas", a assimilação é apenas valorativa, assim como em "os baderneiros".

Nos exemplos a seguir, a categorização do grupo assimilado é feita em termos de identificação com base em critério ideológico:

- SC2.G. há 4 horas: A extrema direita diz que Dilma quer implantar o comunismo. Já a extrema esquerda (PSOL, PSTU) rompeu como o PT por ter traído suas bandeiras e se tornado tão ou mais corrupto do que a direitalha sempre foi. Ou seja, tem avaliação para todos os gostos. (...) [assimilação; identificação ideológica]

A assimilação, nocorpus, realiza-se, lexicogramaticalmente, através de substantivos coletivos (bando, corja, quadrilha); através de substantivos singulares com referência genérica (a direita, a esquerda), ou, ainda, através de substantivos plurais com referência genérica e marcação valorativa (os baderneiros).

Há, ainda, ocorrência de assimilação com base em funcionalização (sindicalistas), ou seja, com categorização do grupo assimilado em termos de sua atividade:

- SC1.DC. há 1 hora: Pelo que entendi, Sindicalistas Oportunistas, MST, CONTAG, Campesinos, UNE, e outros bandos de ONGs e OS que parasitam o dinheiro público em troca de fazer barulho e ser plateia paga de eventos fake do PT, estão tremendo de medo de perderem as boquinhas 
que receberam ao longo de anos sem merecer e, querem fazer bagunça agora? Pro inferno esta cor ja! [assimilação; categorização; associação]

A estratégia de assimilação do outro (esta corja), nesse exemplo, é apoiada na representação do grupo como uma aliança provisória (entre MST, CONTAG etc.), que existe apenas em relação à certa atividade (parasitam o dinheiro público). Há vários outros exemplos de associação no corpus:

- SC1.Acm27. há 1 hora: A corjja de fillhosdddaputtta da UNE e do MST, compradas com dinheiro sujo roubbado do povo, são os "movimentos sociais" que os vagabbundos Lula e Dilma querem jogar contra o povo honesto. [assimilação; categorização; associação]

Codifica-se, nesse sintagma nominal, assimilação por valoração negativa (corja), categorização por funcionalização (em UNE e MST, há representação de atividade), e, finalmente, associação (a aliança que se cria entre as entidades UNE e MST).

A assimilação é uma representação discursiva que contrasta com a individualização, ao reunir os indivíduos em grupos, conferindo-lhes algum traço que os identifique (a esquerda; a direita; os sindicalistas; os baderneiros; os oportunistas). Já na generalização, os atores sociais também são reunidos em grupos, mas não são categorizados, a não ser por um traço abstrato (o povo, o país), como nos exemplos:

- SC2.JSD. há 2 horas: Independente de qual seja o desfecho do TCU ou do TSE, o que o país não suporta mais é tanta incompetência e omissão que está levando o Brasil a um retrocesso político e econômico.(...) [generalização]

- SC2.AJL. há 41 minutos: Enquanto eles não largam o osso, quem sofre é o Povo....Bando de oportunistas. [generalização]

- SC1.M. há 2 horas: essa marcha das margaridas é a maior manifestação chapa branca de que se tem noticia e o pior com dinheiro publico, o povo deveria protestar contra isso também, usam nosso dinheiro para financiar sua revolução vermelha, separando brasileiros [generalização] 
- SC1.ARE. há 3 horas: O que a Dilma \& Lula querem que o PT, CUT, MST, CNBB, MTST e BlackBlocs façam no dia 16?????........Eles irão enfrentar o povo brasileiro nas ruas?!......É isso? [generalização]

A generalização, através de termos como "o povo", "o povo brasileiro", ou "o país", tem, como efeito de sentido, função de opacificar o discurso, reunindo sob uma só rubrica um conjunto de posições dispersas. Tal estratégia ocorre tanto no discurso daqueles que se posicionam contra a presidente, como no discurso de internautas que a apoiam.

Ao lado dessa representação por generalização, observase, ainda, a existência de indeterminação, que também contribui para a opacificação do discurso:

- SC2.MF. há 3 horas: (...) Agora Dilma não rouba e nem precisa de roubar. Agora ela não tem como responder pelas mãos de gente que a decadas rouba alias toda vida o pais foi enxarcado de ladrão [indeterminação]

- SC1.O. há 3 horas: Como tem gente nesse país que depende de corrupção. [indeterminação]

Nos dois exemplos, a indeterminação é alcançada por lexicalização, pelo uso do termo 'gente': "gente que há décadas rouba", "gente que depende de corrupção". Embora o núcleo do sintagma nominal (gente) seja modificado por uma oração relativa restritiva (que rouba, que depende de corrupção), o escopo referencial da expressão continua indeterminado (quem é que rouba? quem depende de corrupção?). A indeterminação tem baixa ocorrência no corpus, como pode ser visto no quadro a seguir, que apresenta informações numéricas apenas para efeitos comparativos.

Quadro 1 - Individualização, Assimilação, Generalização e Indeterminação no corpus

\begin{tabular}{|c|c|c|c|c|}
\hline Corpus & $\begin{array}{c}\text { Individualização } \\
\text { (Dilma, Aécio) }\end{array}$ & $\begin{array}{c}\text { Assimilação } \\
\text { (corja, } \\
\text { baderneiros) }\end{array}$ & $\begin{array}{c}\text { Generalização (o } \\
\text { povo) }\end{array}$ & $\begin{array}{c}\text { Indeterminação } \\
\text { (gente que rouba) }\end{array}$ \\
\hline $\begin{array}{c}\text { Subcorpus 1 + } \\
\text { Subcorpus 2 }\end{array}$ & $47 \%$ & $34 \%$ & $16 \%$ & $1,9 \%$ \\
\hline
\end{tabular}


Os dados numéricos foram calculados a partir do número de ocorrências (tokens) ${ }^{6}$ dos diferentes tipos de categorias no corpus. Por exemplo, a generalização teve três tipos de realização lexicogramatical (o povo, o povo brasileiro, o país). Foi calculado o número de ocorrências desses sintagmas nominais no corpus. Em seguida, totalizou-se o número de ocorrências das quatro categorias para se chegar aos dados estatísticos. A percentagem indica a relação entre o número de ocorrências de uma categoria (por exemplo, generalização) e o total de ocorrências de todas as categorias em discussão (individualização, assimilação, generalização e indeterminação).

\section{Análise e interpretação dos resultados}

Uma das características mais óbvias do corpus é o alto grau de especificação de atores sociais, na forma de nomeação. As ocorrências de nomeação podem ser entendidas como motivadas pela natureza do próprio discurso polêmico, que tende a nomear os seus antagonistas.

Há predominância de diversas formas de nomeação informal, embora haja distância social máxima entre os participantes do discurso. Também tal traço do corpus pode ser atribuído ao funcionamento do discurso polêmico, que se constrói no registro da emoção, com endereçamento direto a seus antagonistas. Esse resultado confirma pesquisa de Amaral (2012) sobre usos da linguagem em contexto de forte emoção, que também aponta para a forma como os internautas, ao expressarem sua indignação, dirigem-se a seus interlocutores em registro íntimo, de grande familiaridade.

Depois da nomeação, a assimilação é a estratégia de representação discursiva mais frequente no corpus, aquela através da qual vemos o trabalho de construção de identidades coletivas. Motivada pela polarização do debate político, a assimilação divide o campo social em dois grupos antagônicos, para ao mesmo tempo discriminar em que bases esses

6 Tokens refere-se à instanciação, ou realização concreta, de determinada estrutura linguística em um texto. grupos funcionam. Essa discriminação varia em função do posicionamento discursivo do internauta.

Os internautas que se posicionam contra a presidente Dilma, por exemplo, adotam estratégias de funcionalização, 
em que os grupos que constituem o campo antagônico são formados com base em suas atividades ("sindicalistas", "campesinos", “ONGs", "estudantes"). Já os que se posicionam favoravelmente à presidente identificam os grupos no campo do Outro predominantemente com base em classe social ("a Elite", "nas 'zelite"'). A representação do Outro com base em divisões ideológicas, embora predomine no discurso a favor da presidente ("a direita", "a direitalha"), também figura no discurso contra a presidente ("a esquerda"), mas com apenas quatro ocorrências. E, finalmente, há grupos formados com base exclusivamente na valoração negativa, sem algum traço que os identifique de forma mais clara ("baderneiros", "oportunistas", "incendiários"). Esta última estratégia é usada nos dois posicionamentos discursivos, tanto a favor ou contra a presidente.

Destaca-se, na assimilação de atores sociais, a estratégia de associação, através da qual constroem-se alianças entre grupos, realizada através de sintagmas nominais complexos, em que há coordenação apositiva ou aditiva ("Sindicalistas Oportunistas, MST, CONTAG, Campesinos, UNE, e outros bandos de ONGs e OS”; "a corjja de fillhosdddaputtta da UNE e do MST"; "o PT, CUT, MST, CNBB, MTST eBblackBlocs").

Essa estratégia de associação, baseada em mecanismos de combinação, pode ser vista como o análogo discursivo da tentativa de se criar equivalências no campo político, nos termos de Laclau. Para o autor (2005, p. 77), existem duas racionalidades distintas no discurso político. Uma é a lógica da diferença, a base do discurso democrático, que reconhece posições que podem ser contraditórias e não antagônicas. A lógica da equivalência, por contraste, baseia-se em relações antagônicas, estabelecidas através de cadeias de equivalência (por exemplo, UNE é a negação de A; MST é a negação de A; PT é a negação de A; portanto, $\mathrm{UNE}=\mathrm{MST}=\mathrm{PT}$ e todos são a negação de A).

Em dada relação antagônica, continua Laclau, a presença de um não deixa que o outro constitua-se completamente, ou seja, a relação de um com o outro exaure a realidade de ambos. A lógica da equivalência é redutora e simplifica o social, enquanto a lógica da diferença é mais sofisticada e amplia o campo social ou político, tornando-o mais complexo. 
No corpus de estudo, apenas os internautas com posicionamento contra a presidente Dilma fizeram uso da estratégia de associação. Uma questão que merece ser posteriormente investigada, em um corpus ampliado, é a ocorrência de estratégias de associação no discurso a favor da presidente.

Outra linha de investigação a ser perseguida prendese à correlação observada entre a representação do Outro antagonista com base em classe social ("prayboy capiau", "a Elite") e o posicionamento a favor da presidente. Em um corpus ampliado, a correlação seria mantida, exclusivamente no posicionamento a favor da presidente? Por outras palavras, apenas os internautas a favor da presidente classificam com base em classe social, espelhando e constituindo uma visão do campo social como uma luta de classes?

Sobre generalização, os termos "o povo", ou "o povo brasileiro", ocorrem tanto no posicionamento a favor ou contra a presidente. Trata-se, assim, de significantes flutuantes, que adquirem valoração (sempre positiva, no corpus) no interior de determinada formação discursiva. Além disso, são significantes vagos o suficiente para incluir vários segmentos da população, inscrevendo uma lógica equivalencial no discurso, característica dos discursos populistas.

O seu efeito de sentido é dividir a sociedade em dois campos antagônicos, reduzindo o pólo sintagmático, por assim dizer, ou o número de posicionamentos interpessoais que podem ser combinados, no campo social. Mais uma marca da polarização característica do discurso polêmico e da lógica da equivalência, que, em vez de mostrar a complexidade das relações sociais, reduz e limita o campo do social.

Para Laclau (2005, p. 81), o termo "o povo" é usado quando um grupo social (plebs) atribui-se o lugar do conjunto de todos os cidadãos (populus), ou seja, quando uma parte da sociedade aspira a ser vista como a sua representante legítima, no que tange às demandas apresentadas ao conjunto da sociedade. Nesse sentido, seria possível dizer, com o sociólogo, que há resíduos do discurso populista em ambos os posicionamentos, contra e a favor da presidente.

Cabe esclarecer esse ponto, retomando a distinção, feita por Laclau, entre discurso democrático e discurso populista. 
Enquanto no discurso democrático o social é feito de diferenças, em que as identidades sociais podem ser contraditórias, no discurso populista as relações entre identidades sociais são de puro antagonismo. No discurso populista, segue o autor, não há uma, mas duas sociedades. E mais, não há discursos capazes de estabelecer diferenças (ou de admitir a natureza plural das lutas sociais), no interior de uma sociedade que trabalha a partir de uma lógica da divisão social.

Quanto à última estratégia de representação de atores sociais observada (a indeterminação), esta não tem ocorrência significativa no corpus de estudo, o que é compatível com a polarização do discurso polêmico, que, ao invés de indeterminar, especifica, individualiza, nomeia, agrupa, e avalia, além de criar associações entre grupos.

Retomando as questões de pesquisa, pode-se dizer que o imaginário político dos brasileiros, pós-campanha eleitoral, é habitado por três tipos de atores sociais, representados discursivamente de forma distinta, em diferentes posicionamentos.

Os "responsáveis" pela crise são individualizados, nomeados e assimilados (ou representados como grupos). No discurso a favor da presidente, eles são um partido político (PSDB); os políticos desse partido; a "direita". No discurso contrário à presidente, os culpados são vários partidos políticos (PT, PSOL, PSTU, PMDB, PP); o governo da presidente Dilma; o ex-presidente Lula; a "esquerda".

Outro conjunto de atores sociais são "os parasitas", representados exclusivamente no discurso contra a presidente: os movimentos sociais; o movimento dos estudantes; os sindicalistas; os recipientes de benefícios sociais; e até o imigrante estrangeiro ("eu trabalho para sustentar um bando de desocupado com bolsa? E trazendo mais africano para entupir o país de oligofrênico?"). Aqui, eles são representados por assimilação, como grupos, e por associação, como alianças temporárias que existem em função de determinado propósito (parasitam o dinheiro público).

O terceiro grupo (as "vítimas" da crise) está representado tanto no discurso contra ou a favor da presidente: o povo; o povo honesto; o país. Curiosamente, esta é uma vítima generalizada, às vezes indeterminada no discurso, que pode estar em qualquer lugar, ou em lugar algum. 
A distribuição de atores sociais por posicionamento discursivo, dentro desse quadro conflitual em particular, pode iluminar aspectos relativos aos sentidos em disputa no imaginário político brasileiro. Uma questão importante aqui é que sentidos são mais opacos no corpus? Estes seriam pontos preferenciais de disputa de sentidos.

Para responder a essa pergunta, a mesma foi desmembrada nas seguintes questões: quem somos nós, no discurso dos que se posicionam contra a presidente? E quem somos nós, no discurso dos favoráveis à presidente? Os dados sugerem que há mais opacidade quando se busca identificar as estratégias de autoperceção no discurso destes últimos. Enquanto há autoapresentação no discurso dos que se opõem à presidente ("[somos] brasileiros cansados de corrupção e desprezo"; "eu trabalho para sustentar um bando de desocupado com bolsa"), a mesma estratégia não ocorre no discurso dos favoráveis à presidente, que não se autoidentificam.

Uma importante linha de investigação é a forma complexa como os sentidos inscritos nesses discursos, no presente, interagem com certas regiões de sentido do imaginário político brasileiro, como o imaginário do descrédito da classe política; o imaginário da corrupção generalizada nos circuitos de poder; o imaginário da ordem estabelecida (e os elementos que a ameaçam). Enquanto os dois primeiros informam a representação dos atores sociais responsáveis pela crise (descrédito da política e corrupção), presente nos dois posicionamentos discursivos, o imaginário dos elementos que ameaçam a ordem social está presente na representação dos "parasitas" do dinheiro público, com ocorrência exclusivamente no discurso contra a presidente.

Finalmente, a segunda questão de pesquisa. Que traços caracterizam a construção de identidades coletivas no Brasil, diante da pluralidade de demandas que caracterizam o cenário político da atualidade? Enquanto o Outro imaginário dos internautas contra a presidente é nomeado, especificado e assimilado com traços que vão além da classe social (sindicalistas; movimentos sociais; organização de estudantes; recipientes de benefícios do governo), o Outro dos internautas a favor da presidente é identificado com base em classe social ("a Elite"; "prayboy capiau”). 
Resguardadas as diferenças na construção imaginária do Outro em posicionamentos distintos, observa-se que os seguintes elementos estruturais, que presidem à construção de identidades no discurso, estão presentes no corpus: classe social ("a Elite"); raça ("africano num país de oligofrênico"); ocupação social ("sindicalistas", "estudantes", "campesinos"); orientação ideológica ("direita", "esquerda"). Apenas gênero, idade e orientação sexual não estão representados no corpus.

Para finalizar, não é possível abstrair a análise da representação dos atores sociais das características discursivas do dispositivo digital, que atribui um determinado lugar para o comentário e para o internauta. Em primeiro lugar, a interação em tempo real favorece a expressão de opinião em registro emocional, o que contribui para a polarização observada. É bem conhecida, nos estudos linguísticos, a relação entre grau de planejamento e teor do discurso (maior planejamento motiva usos de linguagem mais cuidadosos, em registro menos emocional).

Também a anonimidade dos interlocutores favorece a expressão de linguagem polarizada e agressiva. Apesar de os locutores identificarem-se, nada impede que adotem apelidos (como de fato o fazem) ou nomes fictícios, o que abre a possibilidade de abandonarem o trabalho de proteção de face que acompanha o diálogo entre pares. Esses parâmetros são discutidos em estudo cujo foco principal é a ocorrência da linguagem do ódio em mídia digital (BALOCCO; SHEPHERD, 2016).

Cada internauta contribui para a produção de discursos e relações sociais. Os enunciados que produz dão ao Outro antagonista uma consistência e uma solidez que ele não tem. Para dar apenas um exemplo, os significantes "a direita" e "a esquerda" são reificados, no corpus, e assumem uma transparência ilusória, que não corresponde à fragmentação, à complexidade e à pluralidade dos grupos e de suas demandas sociais.

Os efeitos de sentido são bem conhecidos; naturaliza-se a divisão social e perde-se de vista o fato de que as identidades coletivas são produzidas pelo homem, são produtos sociais que têm uma história. Nos termos de Berger \& Luckmann (2004, p. 123), "a reificação constitui o grau extremo do 
processo de objetivação, pelo qual o mundo objetivado perde a inteligibilidade que possui como empreendimento humano [...]".

Nesta pesquisa, tomou-se o imaginário político brasileiro após eleição da presidente Dilma Roussef como objeto de estudo, no entendimento de que o estudo do imaginário social é uma janela privilegiada para a construção de narrativas que pretendem dar conta das causas e origens de crises políticas, ou de outra natureza. Nos termos de Castoriadis (1982, p. 85), "compreender uma sociedade significa, antes de tudo, penetrar e apropriar-se do imaginário social que a unifica".

Argumentou-se, também, pela produtividade e consistência teórico-analítica de modelo de Van Leeuwen, de natureza linguística e sociodiscursiva, para a análise e reflexão sobre o funcionamento do imaginário social.

\section{REFERÊNCIAS}

AMARAL, Marcela da Silva. A linguagem no Twitter: um enfoque sistêmico-funcional. 2012. Dissertação (Mestrado em Linguística) - Universidade do Estado do Rio de Janeiro, Rio de Janeiro, 2012.

AMOSSY, Ruth. La coexistence dans le dissensus: la polémique dans les forums de discussion. Semen, n. 31, 1 abr. 2011. Disponível em 〈http://semen.revues.org/9051〉. Acesso em: 30 jan.2013.

BALOCCO, Ana Elizabeth. O sistema do engajamento aplicado a espaços opinativos na mídia escrita. In: VIAN JR., Orlando (ed.). A linguagem da avaliação em língua portuguesa: estudos sistêmicos com base no Sistema de Avaliatividade. São Carlos: Pedro \& João Editores, 2010, v.1, p. 41-55.

BALOCCO, Ana Elizabeth; SHEPHERD, Tania M.G. A violência verbal em comentários eletrônicos: um estudo sistêmicofuncional. 2016. Em preparação.

BERGER, Peter L.; LUCKMANN, Thomas. A construção social da realidade; tratado de sociologia do conhecimento. Rio de Janeiro: Vozes, 2004. [ed. original 1966] 
CASTORIADIS, A instituição imaginária da sociedade. Trad. Guy Reymond. 2. ed. Rio de Janeiro: Paz e Terra, 1982.

CULPEPER, Jonathan. Impoliteness: using language to cause offence. Cambridge and NY: Cambridge University Press, 2011.

EAGLETON, Terry. Ideology: an introduction. London: Verso, 1991.

FAIRCLOUGH, N. The dialectics of discourse. Disponível em 〈http://www.sfu.ca/cmns/courses/2012/801/1-Readings/ Fairclough\%20Dialectics\%20of\%20Discourse\%20Analysis.pdf . Acesso em: 10 jun. 2015.

FOUCAULT, Michel. A arqueologia do saber. 3. ed. RJ: Forense Universitária, 1987. [ed. original Gallimard, 1969]

LACLAU, Ernesto. Emancipation(s). London: Verso, 2007.

LACLAU, Ernesto. On populist reason. London: Verso, 2005.

LACLAU, Ernesto \& MOUFFE, Chantal. Hegemony and socialist strategy: towards a radical democratic politics. London: Verso, 1985.

PEDRO, Emília Ribeiro (Org.). Análise Crítica do Discurso: uma perspectiva sociopolítica e funcional. Lisboa: Editorial Caminho, 1997.

PINTO, Céli Regina Jardim. Elementos para uma análise de discurso político. Disponível em ‘http://online.unisc.br/seer/ index.php/barbaroi/article/viewFile/821/605. Acesso em: 6 dez. 2012.

VAN DIJK, Teun A. What is political discourse analysis? Belgian Journal of Linguistics, vol. 11, issue 1, p. 11-52, 1997.

VAN LEEUWEN, Theo. The representation of social actors. In: CALDAS-COULTHARD, Carmen Rosa \& COULTHARD, Malcolm (eds.). Readings in critical discourse analysis. London: Routledge, 1996. p. 32-70. 


\section{Abstract \\ The representation of social actors in electronic posts: what characters inhabit Brazilians' political imaginary today?}

The study examines Brazilians' political imaginary after election of president Dilma Roussef, through the investigation of the representation of social actors in electronic posts, published in one particular news site. Laclau $\mathcal{E}$ Mouffe's argument for the discursive nature of the social and of collective identities (1985) is drawn upon, as well as the concepts of polemical discourse (AMOSSY, 2011), ideology (EAGLETON, 1991; PEDRO, 1997) and social imaginary (FAIRCLOUGH, 2015; CASTORIADIS, 1982). On the basis of van Leeuwen's (1996) theoretical framework for the study of the representation of social actors in discourse, the study identifies three types of social actors in the corpus; suggests some correlations between positioning and strategies of discursive representation of social actors; as well as introduces some considerations about the heterogeneous and dynamic nature of the social imaginary.

KEY-WORDS: the representation of social actors; electronic posts; polemical discourse; social imaginary. 